\title{
Perilaku Penyalahgunaan Narkoba Di Kalangan Siswa Sekolah Menengah Atas Negeri 1 Banawa Kabupaten Donggala
}

\author{
Narcotics Abuse Behavior in Senior High School 1 Students of Banawa \\ Kabupaten Donggala \\ ${ }^{(1)}$ Herman, ${ }^{2}$ Arie Wibowo, ${ }^{3)}$ Nurdin Rahman \\ ${ }^{(1)}$ Bagian Promosi Kesehatan, Program Studi Kesehatan Masyarakat, FKM Universitas Tadulako \\ (2) Bagian Ilmu Gizi, Program Studi Kesehatan Masyarakat, FKM Universitas Tadulako \\ (2) ariewibowo220916@gmail.com
}

\begin{abstract}
Abstrak
Penyalahgunaan narkoba kelompok pelajar di Sulawesi Tengah sejumlah 27,9\% (BNN \& PUSLITKES UI, 2014). Kabupaten Donggala termasuk dalam 4 besar prevalensi penyalahguna narkoba tertinggi dimana kelompok pelajar sejumlah 1074 orang dari total 3977 orang penyalahguna dengan populasi berusia antara 10-59 tahun (BNN, 2015). BNNK Donggala melalui seksi rehabilitasi menunjukkan ada peningkatan signifikan jumlah pelajar yang menjalani rehabilitasi setiap tahunnya. Penelitian ini bertujuan untuk mengetahui perilaku penyalahgunaan narkoba di kalangan siswa Sekolah Menengah Atas Negeri 1 Banawa Kabupaten Donggala. Metode yang digunakan dalam penelitian ini adalah kualitatif dengan pendekatan studi kasus. Informan Penelitian sejumlah 12 orang yang ditentukan berdasarkan kriteria tertentu (purposive sampling). Hasil penelitian ini menunjukkan pengetahuan informan belum cukup baik karena kurang paham terhadap informasi yang diterima, hal ini ditunjukkan dimana informan bersikap acuh dan memiliki kecenderungan untuk tetap menggunakan narkoba karena sudah mengalami kecanduan. Peraturan/kebijakan sekolah ditujukan pada upaya-upaya pembinaan dan pengawasan melalui kerjasama dengan pihak terkait. Sekolah aktif mengikuti kegiatan penyuluhan baik di internal sekolah maupun di luar sekolah dengan melibatkan seluruh komponen sekolah. Diharapkan sekolah lebih aktif dalam melakukan edukasi mengenai narkoba dan bahaya penyalahgunaannya, mengoptimalkan peran Guru Bimbingan Konseling serta merumuskan suatu kebijakan tentang pelanggaran narkoba yang menjadi dasar dalam pengambilan keputusan terkait penyalahgunaan narkoba di kalangan siswa.
\end{abstract}

Kata Kunci : Perilaku, Penyalahgunaan, Narkoba, Siswa

\begin{abstract}
Student drug abuse in Central Sulawesi amounts to 27.9\% (BNN \& PUSLITKES UI, 2014). Donggala Regency is included in the top 4 prevalence of the highest number of drug abusers, with a group of 1074 students out of a total of 3977 abusers with populations between the ages of 10-59 years (BNN, 2015). Donggala National Narcotics Agency through the rehabilitation section showed a significant increase in the number of students undergoing rehabilitation each year. This study aims to determine the behavior of drug abuse among students at the 1 Banawa State High School in Donggala District. The method used in this study is qualitative with a case study approach. Research informants were 12 people who were determined based on certain criteria (purposive sampling). The results of this study indicate that the knowledge of the informants is not good enough because they do not understand the information received, this is indicated by the informants being indifferent and having a tendency to continue using drugs because they have experienced addiction. School regulations / policies are aimed at efforts to guide and supervise through cooperation with related parties. Schools actively participate in counseling activities both inside the school and outside the school involving all components of the school. It is hoped that schools will be more active in educating about drugs and the dangers of their abuse, optimizing the role of Counseling Guidance Teachers and formulating a policy on drug abuse that forms the basis of drug abuse-related decision making among students.
\end{abstract}

Keywords: Behavior, Abuse, Narcotics, Students 


\section{PENDAHULUAN}

Narkoba merupakan zat psikoaktif narkotika, psikotropika, dan bahan adiktif lainnya yang jika masuk ke dalam tubuh baik secara oral (dimakan, diminum, ataupun ditelan)), dihisap, dihirup, atau disuntikkan dapat mengubah suasana hati, perasaan dan perilaku seseorang (1). Dampak penyalahgunaan narkoba menyebabkan kerusakan atau gangguan fungsi organ-organ tubuh, kerusakan otak dan perubahan fisik tubuh serta resiko terkena penyakit menular berbahaya seperti hepatitis dan HIV/AIDS akibat penggunaan jarum suntik secara bergantian serta menimbulkan gangguan psikis remaja baik mental, emosional, persepsi diri, kendali diri, dan mampu membuat remaja melakukan tindakan diluar kesadaran (2).

World Drug Report 2017 menyatakan sekitar 255 juta penduduk dunia berusia 15-64 tahun merupakan penyalahguna narkoba dengan estimasi global kematian terkait narkoba sejumlah 207.400 jiwa pertahunnya (3).

Hasil Survey BNN 2014 menyebutkan prevalensi penyalahgunaan narkoba di Indonesia sebesar 2,18\% atau sejumlah 4.022.702 orang, dimana kelompok pelajar penyalahguna narkoba menyumbang angka 27,32\% atau sebanyak 1.099.002 orang dengan korban yang meninggal sebanyak 12.044 per tahunnya (4).

Berdasarkan data BNNK Donggala, kelompok pelajar penyalahguna narkoba sebesar 1074 dari jumlah total 3977 penyalahguna. Seksi rehabilitasi menyebutkan jumlah penyalahguna narkoba pelajar yang mendapatkan tindakan rehabilitasi tahun 2017 sekitar 80 orang. Jumlah tersebut meningkat signifikan dibanding tahun 2016, yaitu sebanyak 42 orang pelajar.

Kecenderungan peningkatan jumlah pengguna dengan korban penyalahgunaan narkoba menunjukkan suatu fakta bahwa narkoba merupakan ancaman yang sangat serius, karena pada kenyataannya banyak kalangan pelajar adalah pengguna narkoba (5).

Faktor penyebab pelajar menggunakan narkoba diantaranya karena rasa ingin tahu yang besar dan adanya pengaruh teman sebaya serta pengaruh dari lingkungan keluarga yang kurang harmonis. Ketersediaan dan kemudahan memperoleh narkoba juga disebut sebagai pemicu seseorang menjadi pecandu narkoba (6). Di kalangan pelajar terutama SMA awal mula perkenalan dengan narkoba biasanya dimulai dari perilaku merokok dan mengkonsumsi minuman beralkohol (7).

Kurangnya pengetahuan akan efek buruk narkotika dan psikotropika sangat mempengaruhi tingkat penyalahgunaannya. Dengan pengetahuan tersebut diharapkan dapat menghindarkan atau meniadakan kesempatan terjadinya penyalahgunaan narkotika dan psikotropika pada remaja (8).

Meskipun Kabupaten Donggala berada pada peringkat 4 penyalahguna narkoba di Sulawesi Tengah tetapi hal yang menjadi perhatian adalah jumlah pelajar yang menyalahgunakan dan menjalani rehabilitasi terus meningkat setiap tahunnya, ditambah luas wilayah yang terbuka terutama laut menjadi pemicu berkembangnya peredaran gelap narkoba khususnya pada pelajar sekolah menengah atas. Berdasarkan latar belakang di atas maka penulis merasa tertarik untuk menggali lebih dalam mengenai perilaku penyalahgunaan narkoba di kalangan siswa Sekolah Menengah Atas Negeri 1 Banawa Kabupaten Donggala.

\section{METODE PENELITIAN}

Jenis penelitian ini adalah kualitatif dengan pendekatan studi kasus. Penelitian ini dilaksanakan di Sekolah Menengah Atas Negeri 1 Banawa Donggala pada bulan Agustus 2018. Penentuan informan dilakukan melalui teknik purposive sampling. Informan kunci adalah Kepala Sekolah dan BNNK Donggala, informan biasa adalah siswa/ 
siswi yang pernah dan masih menggunakan narkoba, dan informan tambahan adalah Guru Bimbingan Konseling dan Wali Kelas.

\section{HASIL PENELITIAN}

\section{Faktor Predisposisi}

Pengetahuan

Wawancara mendalam yang peneliti lakukan kepada informan tentang “apa yang dimaksud dengan narkoba?" diperoleh hasil bahwa sebagian besar siswa/siswi tidak mengetahui pengertian dari narkoba. Ketika ditanyakan tentang “alasan sehingga menggunakan narkoba?” diperoleh hasil bahwa sebagian besar informan menyatakan karena rasa ingin tahu sehingga mau mencoba kemudian adanya pengaruh dari teman pergaulan serta masalah keluarga juga menjadi alasan untuk menggunakan narkoba.

Sikap

Wawancara juga dilakukan untuk melihat "bagaimana sikap siswa/siswi ketika menemukan penyalahgunaan narkoba disekitarnya?”. Diperoleh hasil bahwa informan hanya membiarkan saja meskipun tetap memberi teguran dan nasehat disebabkan mereka merasa serba salah. Ada pula yang bersikap tegas apabila yang didapati menggunakan narkoba adalah kerabat dekat (keluarga). Selanjutnya peneliti menanyakan “apakah masih menggunakan narkoba hingga saat ini?" diperoleh hasil bahwa mereka masih menggunakan narkoba dengan mengemukakan berbagai alasan.

\section{Faktor Penguat}

\section{Peraturan/Kebijakan}

Wawancara mendalam telah dilakukan peneliti kepada informan biasa mengenai "ada tidaknya peraturan sekolah terkait pelanggaran tentang narkoba?" diperoleh hasil bahwa semua siswa/siswi tidak mengetahui tentang peraturan yang mengatur tentang pelanggaran terkait narkoba di sekolah. Sedangkan informan kunci menyatakan bahwa peraturan tentang pelanggaran narkoba tertuang dalam kebijakan yang bertujuan pada perbaikan anak didik melalui pembinaan dan pengawasan serta kerjasama dengan pihak terkait. Ketika peneliti menanyakan tentang “apakah sekolah pernah memberikan sanksi terkait pelanggaran narkoba?”, hasil menunjukkan bahwa sebagian besar informan biasa menjawab pernah yaitu dikeluarkan dari sekolah. Sedangkan informan kunci menyatakan dikeluarkan dari sekolah merupakan langkah terakhir yang ditempuh sekolah apabila pelanggaran yang sama sudah berulang kali dilakukan oleh siswa. Untuk saat ini, sekolah berupaya untuk tetap melakukan pembinaan dan pengawasan. Ditambahkan juga bahwa dalam rangka pencegahan peredaran narkoba, sekolah rutin melaksanakan razia kepada seluruh siswa.

\section{Peran Sekolah}

\section{Memberikan Pengetahuan}

Salah satu peran sekolah dalam pencegahan penyalahgunaan narkoba adalah dengan memberikan pengetahuan yang baik sehingga peserta didik memiliki pemahaman yang baik pula. Ketika menanyakan “apakah sekolah pernah mengikutkan siswa/siswi dalam kegiatan penyuluhan tentang narkoba?" didapatkan hasil bahwa sebagian besar informan mengatakan bahwa mereka pernah mengikuti kegiatan penyuluhan tentang narkoba yang dilaksanakan oleh Badan Narkotika Nasional Kabupaten Donggala. Informan kunci dan informan tambahan juga menyatakan hal yang sama bahwa kegiatan penyuluhan tentang narkoba tidak hanya mengikutkan siswa sebagai pesertanya tetapi Gurupun diikutkan. 


\section{PEMBAHASAN}

\section{Pengetahuan}

Pengetahuan diperlukan sebagai dorongan psikis karena merupakan stimulus terhadap tindakan seseorang. Salah satu penyebab rendahnya pengetahuan adalah karena minimnya informasi yang diterima serta sikap kurang peduli terhadap materi yang disampaikan sehingga berpengaruh pada tingkat pengetahuan seseorang.

Dalam penelitian ini, pengetahuan informan masih kurang karena informan tidak mampu menjelaskan dengan baik pengertian dari narkoba dan termasuk ke dalam pengetahuan tingkat pertama yaitu tahu dan belum masuk pada tingkat aplikasi karena belum mampu menerapkan informasi yang diterima atau dipelajari pada kondisi yang sebenarnya.

Penelitian ini sejalan dengan penelitian yang mengatakan bahwa remaja dengan pengetahuan yang buruk akan beresiko 3,8 kali lebih besar untuk menyalahgunakan narkoba dibandingkan remaja dengan tingkat pengetahuan yang baik (9). Berbeda dengan penelitian lain yang mengemukakan bahwa remaja rentan terhadap penyalahgunaan narkoba meskipun memiliki pengetahuan tentang narkoba (10). Pengetahuan akan efek buruk dari penyalahgunaan zat tidak cukup mencegah para remaja untuk menghentikan penggunaan zat (11).

\section{Sikap}

Dalam penelitian ini, sebagian besar siswa/siswi memiliki sikap pro terhadap penyalahgunaan narkoba. Hal ini ditunjukkan dengan kecenderungan untuk tetap menggunakan narkoba. Sikap tidak peduli juga diperlihatkan informan meskipun mengetahui menyalahgunakan narkoba itu berbahaya bagi diri dan masa depannya.

Sikap informan masuk dalam kategori merespons, yang berarti informan mau mengerjakan tugas yang diberikan terlepas apakah perbuatan itu bermanfaat atau tidak. Merespons ini ditandai bahwa informan tetap mau menggunakan narkoba meskipun mengetahui efek buruk penyalahgunaannya bagi kesehatan.

Penelitian ini sejalan dengan sebuah penelitian yang menunjukkan bahwa siswa sekolah menengah atas di Jakarta memiliki sikap yang positif terhadap penyalahgunaan narkoba, artinya sikap dapat mempengaruhi seseorang dalam pengambilan keputusan sehingga sikap yang positif ini dengan sendirinya akan membahayakan diri para siswa (12). Begitupun dengan penelitian yang menyebutkan pengetahuan yang tidak baik mempertinggi terbentuknya sikap yang tidak baik pula (13).

\section{Peraturan/Kebijakan}

Berdasarkan hasil penelitian menunjukkan bahwa sekolah telah menerapkan aturan berupa kebijakan yang diwujudkan dalam bentuk kerjasama melalui pembinaan dan pengawasan terhadap siswa/siswi yang terlibat penyalahgunaan narkoba agar mendapatkan penanganan yang semestinya serta terus melakukan koordinasi dengan pihakpihak terkait dalam rangka melaksanakan pencegahan dan pemberantasan penyalahgunaan dan peredaran gelap narkoba di sekolah yang melibatkan Badan Narkotika Nasional Kabupaten Donggala, Kepolisian Resort Donggala, dan Rumah Sakit Umum Daerah Kabelota. Meskipun diakui informan ada beberapa siswa yang dikeluarkan dari sekolah disebabkan melakukan pelanggaran yang berat.

Penelitian ini sejalan dengan penelitian yang mengatakan bahwa ada hubungan yang bermakna antara peraturan sekolah dengan efektifitas pencegahan penyalahgunaan narkoba di kalangan siswa yang berarti terdapat keterkaitan antara efektivitas dengan peraturan yang ditetapkan. Untuk mendorong terwujudnya pencegahan penya- 
lahgunaan narkoba diperlukan penguatan aturan dalam aspek implementasi kebijakan agar pembinaan dapat dilakukan secara efektif(14).

\section{Peran Sekolah}

Berdasarkan hasil penelitian yang dilakukan oleh peneliti, didapatkan hasil bahwa sekolah berperan aktif dalam menambah pengetahuan dan pemahaman siswa tentang bahaya narkoba dengan mengikutkan para siswa dalam setiap kegiatan-kegiatan penyuluhan narkoba baik yang dilaksanakan oleh instansi pemerintah maupun organisasi yang konsen terhadap permasalahan narkoba. Sekolah juga rutin melakukan kegiatan penyuluhan melalui organisasi internal sekolah dengan melibatkan guru bimbingan konseling serta siswa-siswi yang tergabung dalam OSIS, Pusat Informasi Konseling Remaja, Pramuka, Unit Kesehatan Remaja, Palang Merah Remaja dan Sanggar Kesenian Sekolah.

Penelitian ini sejalan dengan penelitian yang mengatakan bahwa sekolah merupakan tempat yang paling efektif dalam mencegah penyalahgunaan narkoba dengan jalan memberikan pengetahuan dan pemahaman kepada siswa terkait narkoba dan dampaknya bagi kehidupan baik melalui penyuluhan-penyuluhan ataupun sosialisasi (15).

\section{KESIMPULAN}

Pengetahuan informan tentang narkoba dan bahaya penyalahgunaannya dalam kategori kurang baik dan ditunjukkan dengan sikap yang positif terhadap penyalahgunaan narkoba. Peraturan sekolah yang memuat tentang pelanggaran narkoba adalah berupa kebijakan yang dititik beratkan dalam pembinaan dan pengawasan. Sekolah juga aktif mengikutkan para siswa dalam setiap penyuluhan yang dilakukan oleh instansi-instansi pemerintah terkait ataupun organisasi kemasyarakatan.

\section{UCAPAN TERIMAKASIH}

Terima kasih kepada kepala sekolah SMAN 1 Banawa beserta para dewan guru dan siswa-siswi yang telah membantu dan berkontribusi terhadap hasil penelitian ini. Demikian juga Badan Narkotika Nasional Kabupaten Donggala atas segala bantuan dan dukungannya sehingga penelitian ini dapat selesai seperti yang diharapkan.

\section{DAFTAR PUSTAKA}

1. Kusmiran, Eny. 2012. Kesehatan Reproduksi Remaja dan Wanita. Jakarta: Salemba Medika.

2. BNN. 2009. Advokasi Pencegahan Penyalahgunaan Narkotika Bagi Petugas Lapas Dan Ruta. Jakarta: Pusat Pencegahan Lakhar, BNN.

3. UNODC. World Drug Report 2017. New York: UNITED NATIONS.

4. BNN RI. 2015. Laporan Akhir Survey Nasional Perkembangan Penyalahgunaan Narkoba Tahun anggaran 2014. Jakarta: BNN.

5. Ismail, Wahyuni. 2017. "Teori Biologi Tentang Perilaku Penyalahgunaan Narkoba". Biotek 5: 127-43.

6. Af'idah, Sofia Anisatul. 2016. "Metode Pencegahan Penyalahgunaan Narkoba Berbasis Satuan Tugas Anti Narkoba Sekolah.” Universitas Islam Negeri Sunan Kalijaga, Yogyakarta.

7. Nurmaya, Alya. 2016. Penyalahgunaan Napza Di Kalangan Remaja (Studi Kasus pada 2 Siswa di MAN 2 Kota Bima). Jurnal Psikologi Pendidikan \& Konseling, 2(1), 26-32.

8. Budiartha. 2009. "Data Kasus Narkoba Tahun 2004 s/d 2008." Bali.

9. Idris, Muhammad and Surya Ningrat Salehudin. 2017. "Faktor-faktor yang Mempengaruhi Penyalahgunaan Napza pada Remaja di RT/RW 003/004 Kelurahan Inolobu Kecamatan Wawotobi Kabupaten Konawe”. E Jurnal 
kesehatan.

10. Nkiruka, Ezeokoli Rita., Omosefe, Omozusi Mercy and Phebe, Abraham Chimurunwa. 2017. An Assessment of Adolescents Knowledge and Perceived Susceptibility of Peer Group Relationship on Substance Abuse in Selected Secondary Schools in Ikenne Local Government Area of Ogun State Nigeria. South Journal of Culture and Development Vol 9(1).

11. Stenberg, L. 2005. Cognitive and Affective Development in Adolescence. Trends in Cognitive Sciences, 9;6974.

12. Fitriani, Oki., Handayani Sarah and Nur Asiah. 2017. Determinan Penyalahgunaan Narkoba Pada Remaja di SMAN 24 Jakarta. Arkesmas, 2(1),Jan-Juni.

13. Sunaryo. 2017. "Hubungan Tingkat Pengetahuan Remaja Tentang Narkoba dan Sikap Menggunakan Narkoba Pada Siswa Sekolah Menengah Atas di Kabupaten Sleman.” JKM Stikes Wira Husada Vol.10 No.2/2017.

14. Saepudin, Anas. 2017. Pengaruh Implementasi Program Advokasi Pencegahan Penyalahgunaan Narkoba Terhadap Partisipasi Lembaga Pendidikan Menengah dan Tinggi dalam Mewujudkan Efektivitas Pencegahan Penyalahgunaan Narkoba. Jurnal Publik, Vol.11,No.1:65-74.

15. Juita, Erna Bahrun and Nurhasanah. 2016. "Program Sekolah Dalam Upaya Pencegahan Penyalahgunaan Narkoba Di SMAN 13 dan SMAN 7 Banda Aceh.” Ilmiah Mahasiswa Bimbingan dan Konseling 1 (November): 8-13. 